\title{
AERO GAS TURBINE FLIGHT PERFORMANCE ESTIMATION USING ENGINE GAS PATH MEASUREMENTS
}

\author{
Yi-Guang Li \\ School of Aerospace, Transport and Manufacturing \\ Cranfield University, Cranfield, Bedford MK43 OAL, UK
}

\begin{abstract}
Mature gas turbine performance simulation technology has been developed in the past decades and therefore gas turbine performance at different ambient and operating conditions can be well predicted if good thermodynamic performance software and necessary engine performance information are available. However, the performance of gas turbine engines of the same fleet may be slightly different from engine to engine due to manufacturing and assembly tolerance and may change over time due to engine degradation. Therefore, it is necessary to monitor and track important performance parameters of gas turbine engines, particularly those that cannot be directly measured, to ensure safe operation of the engines.

For that reason, a novel gas turbine performance estimation method using engine gas path measurements has been developed to predict and track engine performance parameters at different ambient, flight, degraded and partload operating conditions. The method is based on the Influence Coefficient Matrix (ICM) of thermodynamic performance parameters of gas turbine engines and the Newton Raphson mathematical algorithm. Contrary to the conventional gas turbine off-design performance predictions where component characteristic maps are essential, it has the advantage that no component characteristic maps are required for the predictions and therefore it is relatively simple thermodynamically, fast in calculation and desirable in engineering applications. It is able to make important invisible performance parameters visible to gas turbine users, which is a useful complement to current engine condition monitoring techniques. The developed method was applied to the performance prediction of a model gas turbine engine similar to EJ200 low bypass turbofan engine running at different altitudes, Mach numbers and part-load, with and without degradation by using simulated gas path measurements to test the effectiveness of the method. The results show that the method is able to predict the engine performance with good accuracy without the consideration of measurement noise and with slightly lower accuracy when measurement noise is included. It takes about 30 seconds for a typical prediction point, which is suitable for off-line
\end{abstract}


performance tracking and condition monitoring. Theoretically, the method can be applied to the performance estimation of any types of gas turbine engines.

\section{NOMENCLATURE}

ACM Adaptation Coefficient Matrix

$B P R \quad$ Bypass ratio

ETA Isentropic efficiency

FC Flow capacity $(\mathrm{kg} / \mathrm{s})$

$H \quad$ Influence Co-efficient Matrix (ICM) / Altitude (m)

HOT Higher order terms

HPC High pressure compressor

HPT High pressure turbine

ICM Influence Coefficient Matrix

$K \quad$ Number of induced performance parameters

LPT Low pressure turbine

$M \quad$ Number of performance parameters

$m_{a} \quad$ Air mass flow rate $(\mathrm{kg} / \mathrm{s})$

$m_{f} \quad$ Fuel flow rate $(\mathrm{kg} / \mathrm{s})$

$N \quad$ Number of measurement parameters

NT Net thrust (N)

$P \quad$ Total Pressure (atm)

$P R \quad$ Compressor pressure Ratio

RMS Root Mean Square

SFC Specific Fuel Consumption (mg/N.s)

$T \quad$ Total Temperature (K)

TET Turbine Entry Temperature (K)

$\vec{w} \quad$ Induced performance parameter vector

$\vec{x} \quad$ Performance parameter vector

$\vec{z} \quad$ Measurement parameter vector 


\section{Greek Letters}

$\sigma \quad$ Convergence threshold

$\varepsilon / \bar{\varepsilon} \quad$ Prediction error/Average prediction error

$\Delta \quad$ Deviation

\section{Subscripts}

$24 \quad$ Fan exit

$3 \quad$ HPC exit

$44 \quad$ HPT exit

$5 \quad$ LPT exit

c1, c2 Fan and HPC, respectively

$\mathrm{t} 1, \mathrm{t} 2$ HPT and LPT, respectively

\section{Superscripts}

\# Pseudo-inverse

T Transpose

$-1 \quad$ Inverse

\section{INTRODUCTION}

Aero gas turbine engine performance is normally assessed by its performance parameters, such as thrust, specific fuel consumption (SFC), compressor pressure ratios, compressor and turbine isentropic efficiencies, turbine entry temperature, engine air flow rate, etc. Some of such information is OEM's exclusive property and may only be partially available to gas turbine users. In addition, some of them cannot be directly or easily measured due to technical difficulties. They may also be slightly different from engine to engine even in the same fleet due to manufacturing and assembly tolerance and engine degradation. Therefore, estimation of these performance 
parameters at different ambient, flight, degraded and part-load conditions can be very useful for engine condition monitoring and engine control.

Conventional design point and off-design performance simulation techniques, such as those published in [13], are based on fundamental thermodynamics and empirical engine information such as component characteristic maps. Customer decks for production engines provided by OEMs are good examples of such technology in helping gas turbine users understand engine performance during operation. These techniques are very useful in predicting gas turbine engine performance when ambient, flight, health and engine operating conditions are available and can be very accurate for individual engines when the empirical engine information are accurate. However, a performance model for an engine fleet may have noticeable prediction errors for individual engines due to manufacturing and assembly tolerance. In addition, actual performance of gas turbines is changing over time due to gradual performance degradation, which will result in increasing prediction errors of the model. Therefore, a performance model generated for fleet engines may not be good enough for the purpose of condition monitoring.

Gas turbine performance adaptation is a type of techniques of adapting engine performance models to real engine performance in order to have accurate engine performance prediction at both design and off-design operating conditions. Different adaptation techniques have been developed in the past. For example in 1990 Stamatis et al. [4] introduced a performance adaptation method to improve performance model accuracy by modifying component maps using introduced modification factors and a non-linear generalised minimum residual method. Stamatis et al. [5] introduced a sensitivity analysis and a fast selection procedure to optimize the modification factors in 1992. Lambiris et al. [6] further improve the method in 1994 by introducing a weighted error function and a polytope algorithm to optimise modification factors. Roth et al. [7] introduced an optimization concept for engine cycle model matching and a minimum variance estimator algorithm [8] for performance matching of a turbofan engine. Kong et al. proposed map scaling methods using Genetic Algorithms to improve the accuracy of performance models [9-10]. Li et al. developed an Influence Coefficient Matrix based adaptation method for gas turbine design point performance adaptation [11] and different non-linear adaptation methods using Genetic Algorithm to improve the accuracy of off-design performance modelling [12-14]. More recent development of off-design performance adaptation has been published by Tsoutsanis et al. [15-17].

In this research, a design point performance adaptation method is further developed and used in the prediction of real gas turbine engine performance based on engine gas path measurements. The developed method 
was tested by applying the method to the performance prediction of a model aero low bypass ratio turbofan engine similar to EJ200 by using simulated gas path measurements of the model engine running at different flight, degraded and part-load operating conditions. The results of the prediction are demonstrated and relevant discussions and conclusions are provided accordingly.

\section{METHODOLOGY}

Traditionally in gas turbine performance simulation, an engine thermodynamic performance model may be set up first at a chosen "design point" where the performance information, such as compressor pressure ratios, compressor isentropic efficiencies, turbine entry temperature, turbine isentropic efficiencies, air flow rate, etc. of the engine at this specific operating point are given and the engine design point performance is calculated. The performance of the engine at off-design conditions, i.e. at different ambient, flight and health conditions and/or at different power levels, can be predicted by using thermodynamics, empirical component maps and mathematical algorithms to achieve a new engine thermodynamic equilibrium condition where the continuity of mass, momentum and energy are satisfied. With the development of advanced gas turbine thermodynamic performance modelling techniques, such off-design performance simulation has been very successful as long as the engine component characteristic maps are accurate and kept unchanged during engine operation. However, prediction errors for individual engines may appear even for the same fleet engines due to manufacturing and assembly tolerance and even for the same engines when their performance degrade during their operation. This is because of the difference between the component characteristic maps used in the performance models and those of real engines.

The idea of the introduced performance estimation method is based on an assumption that each off-design operating point can be regarded as an "artificial design point" of the engine. In other words, when a gas turbine engine thermodynamically reaches its equilibrium condition at an off-design point, the actual performance status of the engine represented by key performance parameters, such as compressor pressure ratios and isentropic efficiencies, turbine entry temperature, turbine isentropic efficiencies, engine air flow rate, etc., may be estimated with a design point performance adaptation method by matching all predicted gas path parameters to the corresponding available gas path measurements. 
The estimation of off-design performance of an engine is an inverse mathematical problem. In other words, the information of the independent variables of an engine thermodynamic system is estimated by using the information of the dependent variables of the system available in engine gas path measurement. The idea and the mathematical representation of the performance estimation approach are described as follows.

In the introduced performance estimation method, it is assumed that each off-design operating point is regarded as an "artificial design point" so that design point performance calculation methods can be applied. Such assumption brings an advantage that no component characteristic maps are required and the thermodynamic performance calculations of gas turbine engines at off-design conditions become simpler and faster than that of the conventional off-design performance calculations. In such performance estimation method, three types of parameters are defined as follows:

1. Engine performance parameters $\vec{x}$ representing and determine the performance of gas turbine engines. These parameters are independent parameters of engine thermodynamic systems and in most cases cannot be easily measured directly. Examples of such parameters are engine air flow rate, compressor pressure ratios and isentropic efficiencies, turbine entry temperature, turbine isentropic efficiencies, cooling flows, etc.

2. Engine gas path measurement parameters $\vec{z}$. They are dependent parameters of the engine thermodynamic systems and can be measured satisfactorily in practice. Examples of these parameters are gas path pressures and temperatures, fuel flow rate, etc.

3. Induced performance parameters $\vec{w}$. They are dependent parameters of the engine thermodynamic systems and indicate important engine performance. They may not be easily measured during engine operation but can be predicted satisfactorily once the engine performance models are established. Examples of these parameters are thrust and SFC.

The thermodynamic relationship between engine performance parameters, induced performance parameters and engine gas path measurement parameters can be represented by Equations (1) and (2)

$$
\begin{aligned}
& \vec{z}=h(\vec{x}) \\
& \vec{w}=g(\vec{x})
\end{aligned}
$$


where $\vec{z} \in R^{N}$ is the gas path measurement parameter vector and $N$ the number of the parameters, $\vec{x} \in R^{M}$ is the engine performance parameter vector and $M$ the number of the parameters, $\vec{w} \in R^{K}$ is the induced performance parameter vector and $K$ the number of the parameters, and $h()$ and $g()$ are vector-valued functions representing the relevant thermodynamic relationship.

A design point thermodynamic performance model for an engine at a specified flight, health and operating condition, i.e. at an "artificial design point", may initially be built up with assumed values of the performance parameters $\vec{x}$ and such a model can be used as a baseline model, which is denoted by subscript 0 . Therefore, Equation (1) can be expanded in a Taylor series around the baseline condition and becomes Equation (3).

$$
\vec{z}=\vec{z}_{0}+\left.\frac{\partial h(\vec{x})}{\partial \vec{x}}\right|_{0}\left(\vec{x}-\vec{x}_{0}\right)+\text { HOT }
$$

where $H O T$ represents higher order terms of the expansion and can be neglected. Correspondingly, a linearized relationship between the deviation of the performance parameters and the deviation of the gas path measurement parameters of a gas turbine engine around the baseline point can be expressed by Equation (4).

$$
\Delta \vec{z}=H \cdot \Delta \vec{x}
$$

where $H$ is called Influence Coefficient Matrix (ICM). The deviation $\Delta \vec{z}$ may be regarded as the difference between the actual and the predicted values of the gas path measurement parameters while the deviation $\Delta \vec{x}$ may be regarded as the difference between the true and the initial values of the performance parameters. The objective of the performance estimation is to search for the values of $\Delta \vec{x}$ in order to minimize the values of $\Delta \vec{z}$ in order to find the estimation of the true values of $\vec{x}$ that represents the real performance status of the engine at a specified flight, health and operating condition.

Mathematically, $\Delta \vec{x}$ can be predicted by inverting the ICM $H$ to an Adaptation Co-efficient Matrix (ACM) $H^{-1}$ leading to Equation (5) when $H$ is a square matrix and invertible.

$$
\Delta \vec{x}=H^{-1} \Delta \vec{z}
$$

If the number of performance parameters is not the same as that of the measurement parameters, $H$ is not a square matrix and its inverse matrix may be replaced by a pseudo-inverse matrix. In other words, If $N>M$ Equation (4) is under-determined and a pseudo-inverse matrix defined by Equation (6) to replace $H^{-1}$ in Equation (5) is the best in a least-squares sense. 


$$
H^{\#}=H^{T}\left(H H^{T}\right)^{-1}
$$

Similarly if $N<M$, Equation (4) is over-determined and a pseudo-inverse matrix defined by Equation (7) to replace $H^{-1}$ in Equation (5) is also the best in a least-squares sense.

$$
H^{\#}=\left(H^{T} H\right)^{-1} H^{T}
$$

$\vec{x}=\vec{x}_{0}+\Delta \vec{x}$ represents the estimated real performance status of an engine at the specified flight, health and operating condition and its prediction based on the above theory is linear in nature and could provide a good estimation when the correction is small and the thermodynamic behaviour of Equation (1) around the baseline condition is close to linear. When the nonlinearity of the relationship between the performance parameters and the gas path measurement parameters is significant, the predicted $\Delta \vec{x}$ may be far from accurate and the Newton Raphson iterative method adopted from [18] may be used where the linear prediction is iteratively applied until a converged solution is obtained. This nonlinear prediction method is schematically illustrated in Figure 1.

To improve the convergence of the nonlinear prediction, under-relaxation may be used and its mathematical representation is shown in Equation (8).

$$
\vec{x}_{i+1}=\vec{x}_{i}+\delta \cdot \Delta \vec{x}_{i}
$$

where $\delta$ is an under-relaxation factor that may take a value between 0 and $1, i$ represents current iteration and $i+1$ represents the next iteration. The determination of $\delta$ is a compromise between the computation speed and the stability of the iteration. In other words, a large value of $\delta$ may result in quick corrections but may result in divergence, and a small value of $\delta$ may have slow corrections but may result in an easy convergence.

The convergence of the nonlinear estimation process shown in Figure 1 is declared when the predicted gas path measurements are very close to the actual values of the measurements. This criterion is shown in Equation (9) where the Root Mean Square (RMS) of the errors must be smaller than a threshold $\sigma$ when a convergence is declared

$$
R M S=\sqrt{\frac{1}{N} \sum_{i=1}^{N}\left(\frac{z_{i, p r e d i c t e d}-z_{i, a c t u a l}}{z_{i, a c t u a l}}\right)^{2}}<\sigma
$$

where $\sigma$ may be chosen to be a very small number, such as 0.001 . 


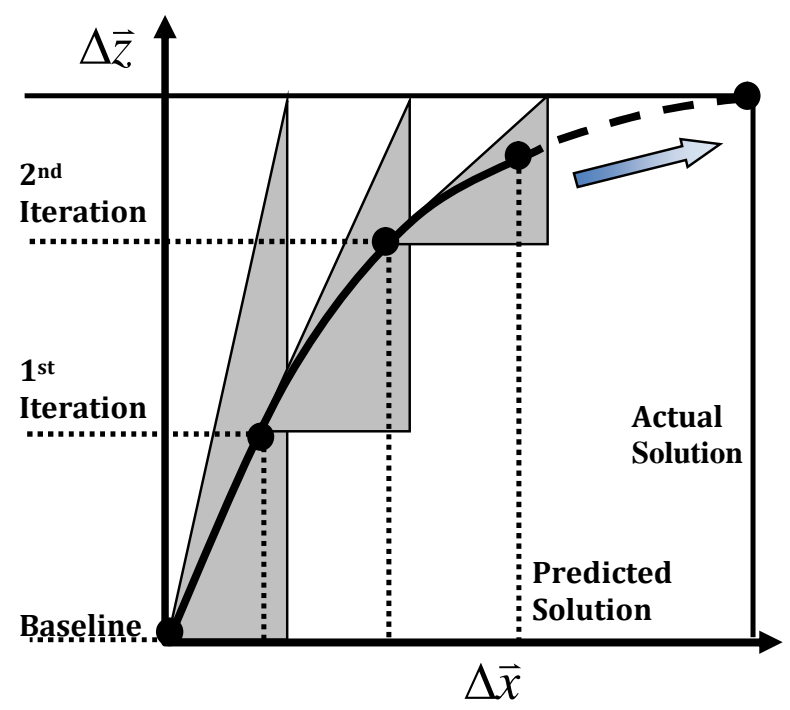

Figure 1: Newton Raphson Method for Performance Estimation [18]

The prediction error for each measurement parameter is defined by the relative difference between the predicted and the actual value of the measurement parameter and is represented by Equation (10).

$$
\varepsilon_{i}=\frac{z_{i, \text { predicted }}-z_{i, \text { actual }}}{z_{i, \text { actual }}} \times 100 \%
$$

where $\varepsilon_{i}$ is the error for the $i_{t h}$ measurement parameter.

The selection of the performance parameters and the gas path measurement parameters plays a crucial role in the success of the performance estimation and ensuring the convergence of the nonlinear prediction approach. Generally a set of selected performance parameters should be able to determine and represent unique performance of a gas turbine engine. Typical performance parameters are compressor pressure ratios and isentropic efficiencies, turbine entry temperature (or combustor exit temperature), turbine isentropic efficiencies, engine air flow rate, etc. Some other performance parameters, such as cooling air and bleeding air, could be included but are normally ignored as they have second order impact. In the selection of gas path measurement parameters, the major considerations are as follows:

- The selected measurement parameters should sensitively respond to the change of performance parameters

- Each performance parameter should have at least one measurement parameter sensitively responding to its change 
- The number of measurement parameters should be close to the number of performance parameters although these numbers are allowed to be different.

Trial and error may be carried out to test the effectiveness of the selected performance parameters and measurement parameters to ensure good selection of these parameters. In addition, a sensitivity analysis may be conducted to assist the selection of the measurement parameters where a unit change to each of the performance parameters may be seeded to the performance model and the response of the measurement parameters may be checked and compared with each other in a bar chart. An example of the sensitivity analysis will be shown in a later part of the paper.

\section{APPLICATION AND ANALYSIS}

\section{A. Model Engine}

The introduced performance estimation method was applied to a model two-spool gas turbine engine similar to EJ200 low bypass ratio aero turbofan engine. The major gas path components of the model engine include a fan driven by a low pressure turbine (LPT), a high pressure compressor (HPC) driven by a high pressure turbine (HPT), a combustor, and a mixed flow convergent-divergent nozzle. The HP shaft speed of the engine is used as the handle of the model engine. The thermodynamic performance model of the engine was set up by using Cranfield gas turbine performance and diagnostic software Pythia [19] where the developed performance estimation method has been implemented. The model engine configuration is schematically shown in Figure 2.

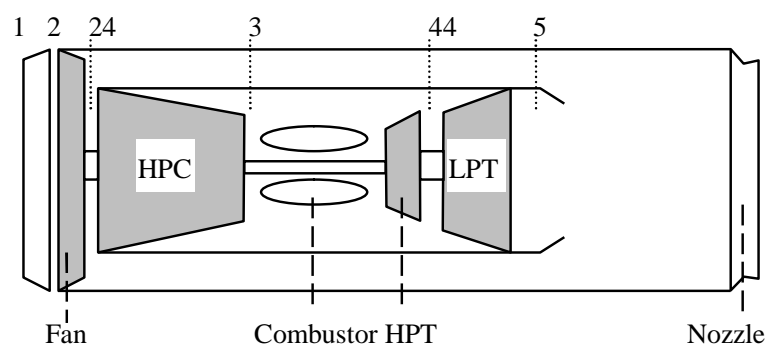

Figure 2: Schematics of Model Engine Configuration 
Table 1: Performance Parameters and Induced Performance Parameters

\begin{tabular}{|l|c|}
\hline \multicolumn{1}{|c|}{ Performance Parameters } & Symbol (Unit) \\
\hline Fan pressure ratio & $P R_{c l}$ \\
\hline Fan isentropic efficiency & $E T A_{c l}$ \\
\hline HPC pressure ratio & $P R_{c 2}$ \\
\hline HPC isentropic efficiency & $E T A_{c 2}$ \\
\hline HPT isentropic efficiency & $E T A_{t 1}$ \\
\hline LPT isentropic efficiency & $E T A_{t 2}$ \\
\hline Bypass ratio & $B P R$ \\
\hline Engine air flow rate & $m_{a}(\mathrm{~kg} / \mathrm{s})$ \\
\hline Turbine entry temperature & $T E T(K)$ \\
\hline \hline Induced Performance & \\
\hline Parameters & \\
\hline Net thrust & \\
\hline Specific fuel consumption & \\
\hline
\end{tabular}

\section{B. Selection of Performance Parameters and Measurement Parameters}

The selected model engine performance parameters and induced performance parameters are shown in Table 1 . To estimate the actual performance of the engine, the gas path measurement parameters selected for the performance estimation are shown in Table 2.

In order to check the functional relationship between the performance parameters and the gas path measurement parameters, a sensitivity analysis was conducted and the results are shown in Figures 3(a) and 3(b). The figures represent the response of each of the gas path measurement parameters to $1 \%$ increase of each of the performance parameters. Such information provides the sensitivity of the gas path measurement parameters to the performance parameters and is very useful in assisting or assessing the selection of the measurement parameters for the performance estimation based on the guidance described in an earlier section of the paper.

As the quality of the performance estimation depends on a strong functional relationship between the performance parameters and the gas path measurements, it is crucial that each of the performance parameters has 
at least one gas path measurement parameter responding sensitively to its variation. If some gas path measurements are not available or get lost in flight, some performance parameters may not be predicted satisfactorily. Therefore proper selection of gas path measurements and keeping them available are very important to ensure the success of performance estimation.

Table 2: Measurement parameters

\begin{tabular}{|l|c|}
\hline Measurement Parameters & Symbol (Unit) \\
\hline Fan outlet total temperature & $T_{24}(\mathrm{~K})$ \\
\hline Fan outlet total pressure & $P_{24}(\mathrm{~atm})$ \\
\hline HPC outlet total temperature & $T_{3}(\mathrm{~K})$ \\
\hline HPC outlet total pressure & $P_{3}(\mathrm{~atm})$ \\
\hline HPT outlet total temperature & $T_{44}(\mathrm{~K})$ \\
\hline HPT outlet total pressure & $P_{44}(\mathrm{~atm})$ \\
\hline LPT outlet total temperature & $T_{5}(\mathrm{~K})$ \\
\hline LPT outlet total pressure & $P_{5}(\mathrm{~atm})$ \\
\hline Fuel flow rate & $m_{f}(\mathrm{~kg} / \mathrm{s})$ \\
\hline
\end{tabular}

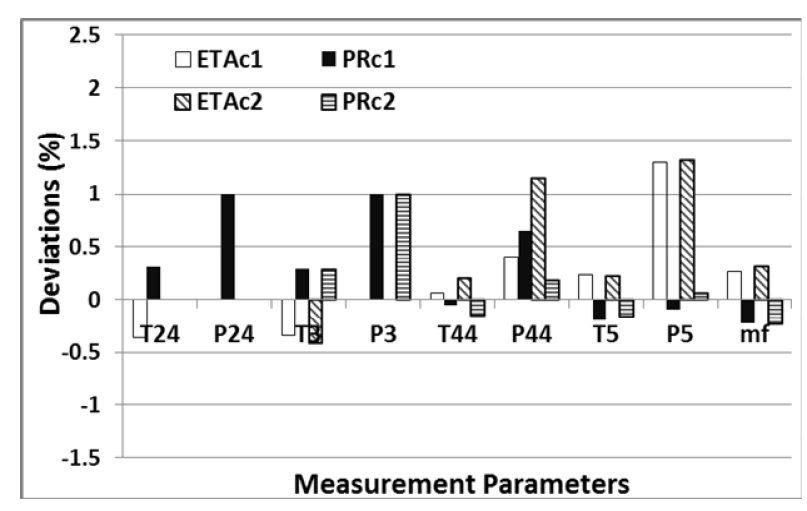

Figure 3(a): Sensitivity Analysis 


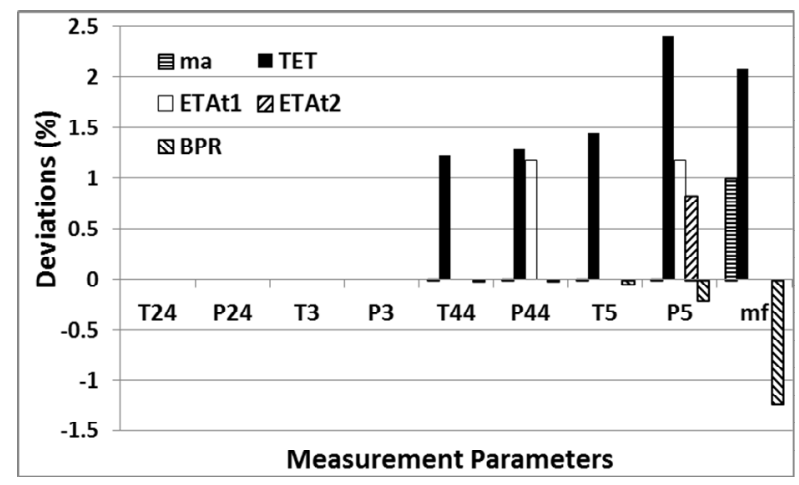

Figure 3(b): Sensitivity Analysis

Table 3: Most Sensitive Measurement Parameters

\begin{tabular}{|l|l|}
\hline \multicolumn{1}{|c|}{ Performance } & \multicolumn{1}{|c|}{ Most Sensitive } \\
\hline$P R_{c 1}$ & Measurement Parameters \\
\hline$E T A_{c 1}$ & $P_{24}, P_{3}$ \\
\hline$P R_{c 2}$ & $P_{3}$ \\
\hline$E T A_{c 2}$ & $P_{44}, P_{5}$ \\
\hline$E T A_{t 1}$ & $P_{44}, P_{5}$ \\
\hline$E T A_{t 2}$ & $P_{5}$ \\
\hline$m_{a}$ & $m_{f}$ \\
\hline$B P R$ & $m_{f}$ \\
\hline$T E T$ & $P_{5}, m_{f}, T_{5}, P_{44}, T_{44}$ \\
\hline
\end{tabular}

Based on the information provided in Figures 3(a) and 3(b), Table 3 shows the most sensitive measurement parameters to each of the performance parameters. In other words, for each of the performance parameters the measurement parameters that have close to or more than $1 \%$ response to the $1 \%$ change of the performance parameters are listed in Table 3.

It can be seen in Table 3 that each performance parameter has at least one measurement parameter that has good functional relationship with it. For example, TET has the highest number of sensitive measurement parameters while $P R_{c 2}, E T A_{t 2}, m_{a}$, and $B P R$ have only one sensitive measurement parameter. Deviation of $E T A_{c 2}$ results in a large deviation of $P_{44}$ and $P_{5}$ due to that the isentropic efficiency of a compressor has a significant 
impact on its downstream total pressure. In addition, it can be seen that $P_{5}, P_{3}$ and $m_{f}$ are crucial for the estimation of some of the performance parameters as they are the only measurement parameters that sensitively respond to the change of the performance parameters.

\section{Simulation of Gas Path Measurement Parameters}

The values of the gas path measurement parameters shown in Table 2 are simulated by running the engine model at three different altitudes $(4 \mathrm{~km}, 8 \mathrm{~km}$ and $12 \mathrm{~km})$ and at Mach Numbers between 0 and 1.6 without engine degradation (i.e. clean engine). Figures 4 and 5 show an example of the simulated gas path measurements of $T 5$ and $m_{f}$ of the clean engine at flight, respectively.

These simulated measurement samples represent the information that may be available from the measurement systems of real aero gas turbine engines at flight and may be used for engine performance estimation and analysis. In this particular case, measurement noise are not considered so the simulated measurements are used as the samples of the measurement parameters.

The above results were obtained by assuming the HP shaft speed as the engine handle and hold constant during flight. However, other parameters, such as LP shaft speed, TET or engine pressure ratio, may also be selected instead as the engine handle, which may result in different performance of the engine at flight. In theory, the performance of an engine working at any steady state conditions can be predicted by the introduced performance estimation method no matter how an engine handle is selected.

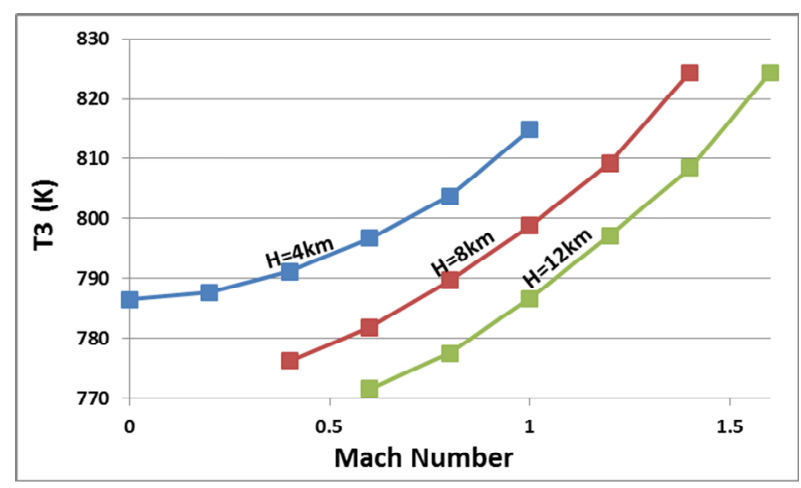

Figure 4: Simulated Measurement $T_{3}$ of Clean Engine at Flight 


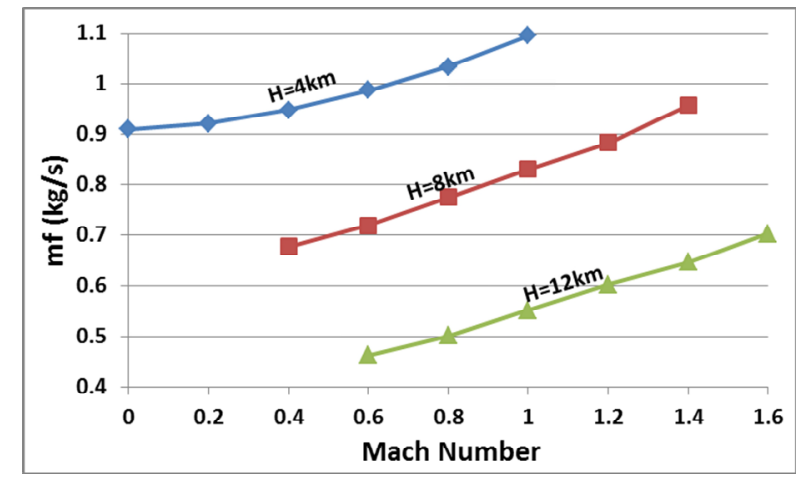

Figure 5: Simulated Measurement $m_{f}$ of Clean Engine at Flight

To demonstrate the capability of the introduced performance estimation method when it is applied to the degraded model engine at flight, a simultaneous degradation of LPC (fan) and HPT shown in Table 4 were seeded into the model engine. Correspondingly, the gas path measurements shown in Table 2 of the clean and the degraded model engine flying at $8 \mathrm{~km}$ at Mach number between 0.4 and 1.4 were also simulated. An example of a comparison of the simulated measurement samples of $T_{3}$ and $m_{f}$ of the clean and the degraded model engine are shown in Figures 6 and 7. The comparison indicates that when the model engine is degraded, its performance as well as the gas path measurements will deviate from their original values. It also indicates that the engine thermodynamic performance model created initially for the clean engine is no longer accurate for the degraded engine.

Table 4: Assumed Engine Degradation

\begin{tabular}{|c|l|c|}
\hline \multicolumn{2}{|c|}{ Component } & Degradation (\%) \\
\hline \multirow{2}{*}{$\begin{array}{l}\text { LPC } \\
\text { (fan) }\end{array}$} & Flow Capacity Index & -3.0 \\
\cline { 2 - 3 } & Efficiency Index & -1.0 \\
\hline \multirow{2}{*}{ HPT } & Flow Capacity Index & -3.0 \\
\cline { 2 - 3 } & Efficiency Index & -1.0 \\
\hline
\end{tabular}




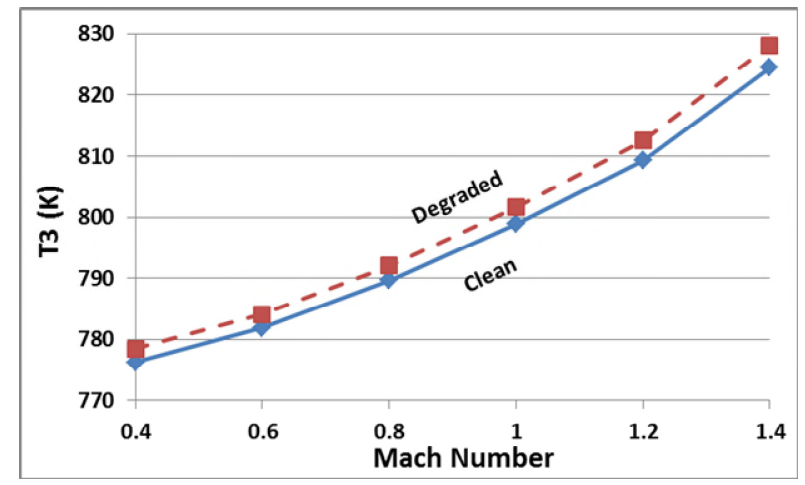

Figure 6: Simulated Measurement $T_{3}$ of Clean and Degraded Engine at Altitude 8km

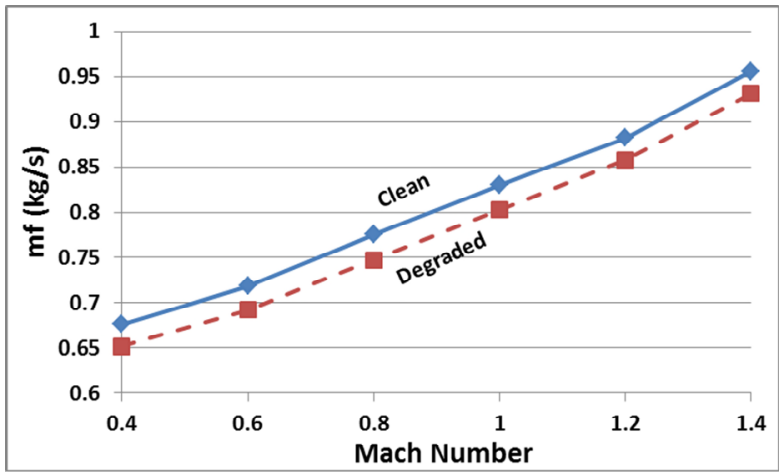

Figure 7: Simulated Measurement $m_{f}$ of Clean and Degraded Engine at Altitude 8km

To demonstrate the capability of the performance estimation method at engine part-load conditions, the gas path measurement parameters (Table 2) of the model engine at different HP rotational speed were also simulated and are shown in Figures 8 and 9.

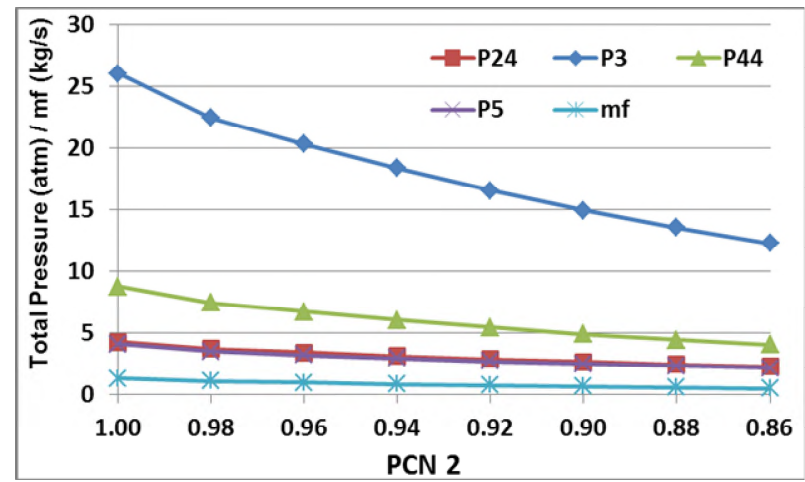

Figure 8: Simulated Measurement $P_{24}, P_{3}, P_{44}, P_{5}$ and $m_{f}$ at Engine Part Load 


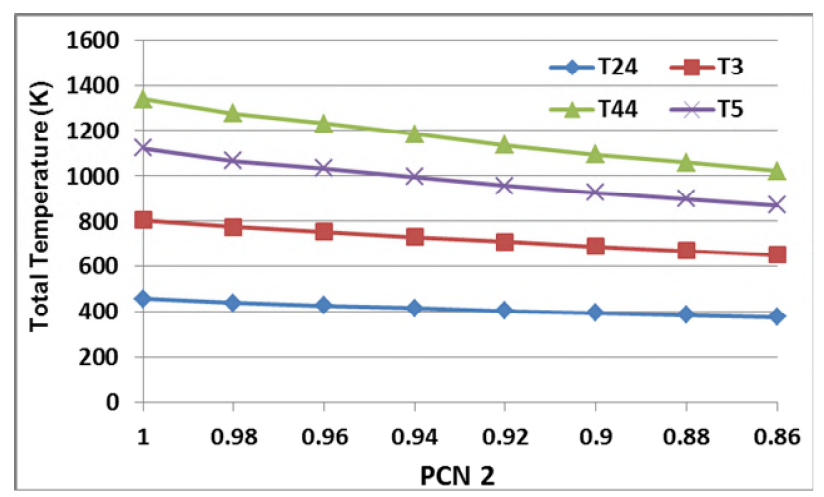

Figure 9: Simulated Measurement $T_{24}, T_{3}, T_{44}, T_{5}$ and $m_{f}$ at Engine Part Load

\section{Performance Estimation of Engine at Flight}

By applying the novel performance estimation method to the clean model engine running at altitudes of $4 \mathrm{~km}$ (Mach number 0 to 1.0), $8 \mathrm{~km}$ (Mach number 0.4 to 1.4) and 12km (Mach number 0.6 to 1.6) using the simulated gas path measurements, important engine performance parameters shown in Table 1 were predicted and the results are shown in Figures 10 to 12. Figure 10 shows a comparison of the actual and the predicted values of the fan and the HPC isentropic efficiencies at different Mach numbers and flight altitudes, respectively. Figures 11-14 show a comparison of the actual and the predicted values of the turbine entry temperature (TET), the engine air flow rate, the net thrust and the SFC of the model engine at different Mach numbers and flight altitudes, respectively.

It can be seen from the figures that the predicted performance parameters agree well with the actual values of the same parameters. The prediction errors are assessed by an average error $\bar{\varepsilon}$ defined by Equation (11).

$$
\bar{\varepsilon}=\sum_{i=1}^{L} \frac{\left|\varepsilon_{i}\right|}{L}=\sum_{i=1}^{L} \frac{\left|x_{i, \text { predicted }}-x_{i, \text { actual }}\right|}{x_{i, \text { actual }} \cdot L} \times 100 \%
$$

where $L$ is the number of prediction points. The average prediction errors for all the performance parameters at different altitudes and Mach numbers are shown in Figure 15. It can be seen that the average prediction errors for most of the performance parameters are below $0.1 \%$ with an exception of around $0.36 \%$ for $B P R$. The net thrust and the $S F C$ are classified as the induced performance parameters and they have relatively large average prediction errors of around 1.6 2.1\%. As the method is based on the ICM and the Newton Raphson iterative calculations, the accuracy of the predictions is determined mainly by the functional relationship between the performance parameters and the gas path measurement parameters. Such functional relationship is well presented by the sensitivity analysis shown in Figures 3(a) and 3(b). In other words, a strong functional relationship will 
benefit the accuracy and vice versa. It can be seen in Figures 3(a) and 3(b) that the sensitivity is different for different parameters and this is the main cause of the prediction errors. The relatively large prediction errors of the net thrust and the SFC are the accumulative effect of the prediction errors of the performance parameters.

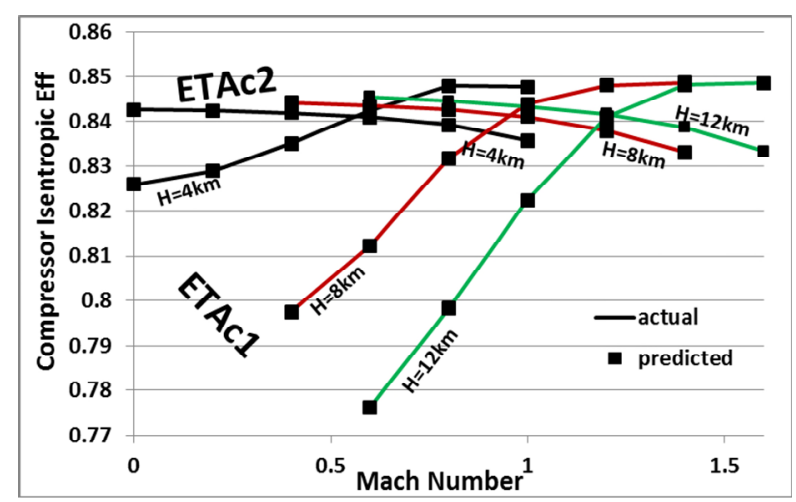

Figure 10: Comparison of Actual and Estimated Compressor Isentropic Efficiencies of Clean Engine at Flight

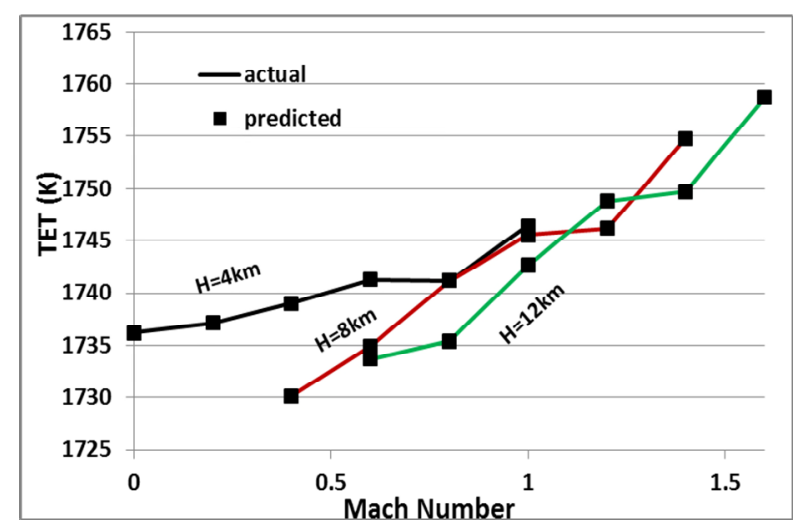

Figure 11: Comparison of Actual and Estimated Turbine Entry Temperature of Clean Engine at Flight 


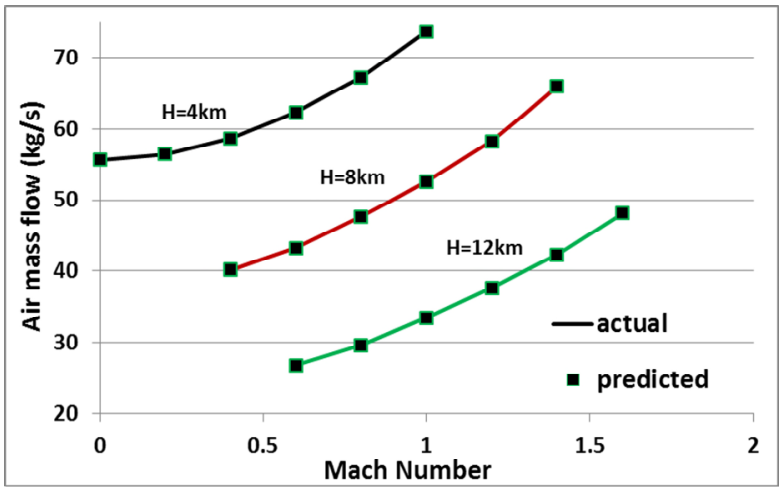

Figure 12: Comparison of Actual and Estimated Air Mass Flow of Clean Engine at Flight

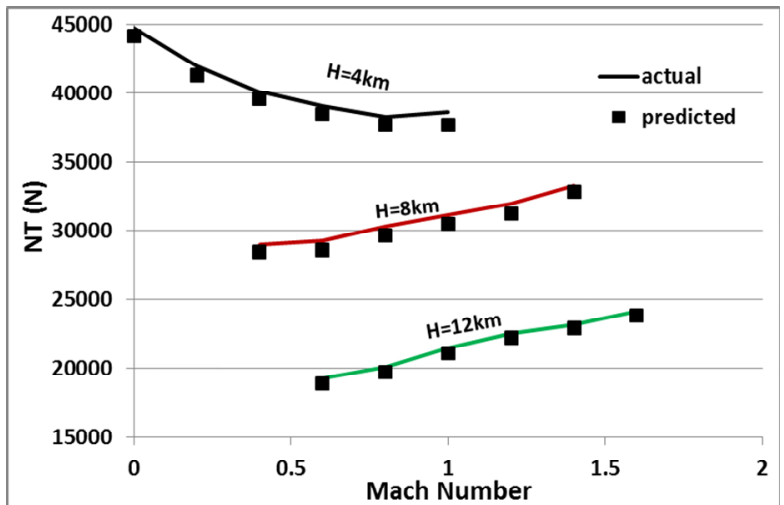

Figure 13: Comparison of Actual and Estimated Net Thrust of Clean Engine at Flight

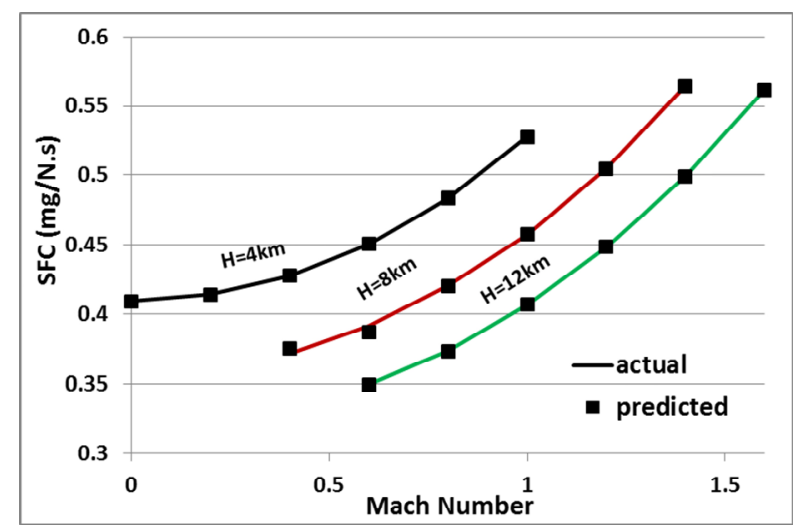

Figure 14: Comparison of Actual and Estimated SFC of Clean Engine at Flight 


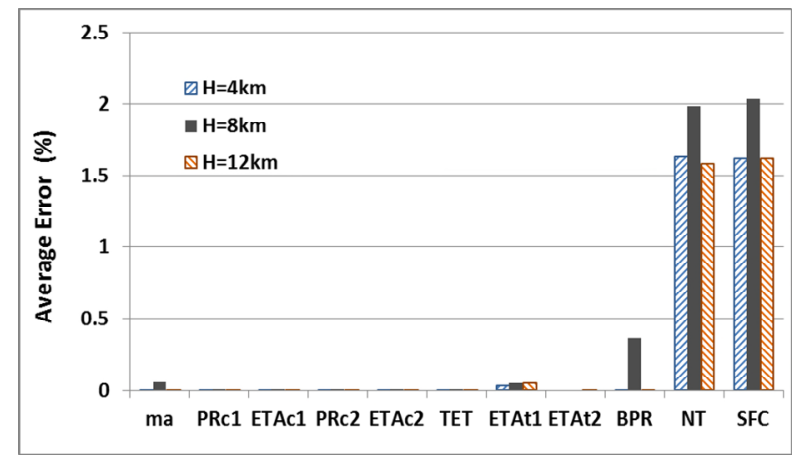

Figure 15: Average Prediction Errors for Performance Parameters of Clean Engine

\section{E. Degraded Performance Estimation of Engine at Flight}

The degraded engine performance of the model engine is determined by the engine degradation, ambient and flight conditions and the selected engine handle. By applying the performance estimation method to the simulated gas path measurements (Figures 6 and 7) of the degraded model engine at an altitude of $8 \mathrm{~km}$ with Mach number between 0.4 and 1.4, the predicted performance of the engine is shown in Figures 16 to 20 with a comparison to that of the clean engine. It can be seen that the predicted values of the performance parameters agree very well with the actual values of the performance parameters except the net thrust and the SFC. The average prediction errors for the performance parameters are shown in Figure 21 where most average prediction errors are very small with an exception of $0.12 \%$ for $B P R$ and $0.24 \%$ for $E T A_{t l}$. The average prediction errors for the induced performance parameters, the net thrust and the SFC, are relatively large and they are around $2 \%$. On the other hand, it can be seen that the TET, the engine air flow rate and the thrust all decrease compared with those of the clean engine. These variations are consistent with the drop of the fuel flow rate of the degraded engine shown in Figure 7.

It is worth mentioning that the baseline engine performance model may only be able to accurately predict clean engine performance and the prediction errors will increase once the engine starts to degrade. By using the introduced performance estimation method, the performance parameters of gas turbine engines can be successfully estimated even when the engines are degraded. Therefore, such performance estimation method can be used as an effective technique to track the degraded engine performance and provide very useful performance information for engine condition monitoring and condition based engine control. 


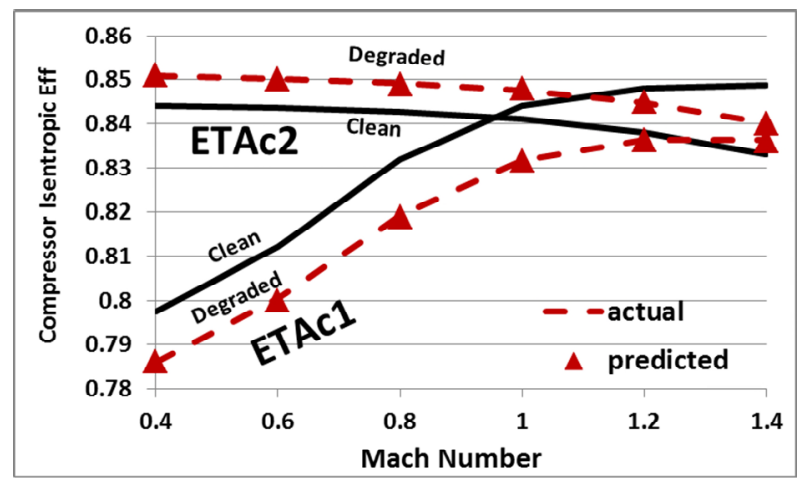

Figure 16: Prediction of ETA of Degraded Engine at $\mathrm{H}=8 \mathrm{~km}$ and Their Comparison with Actual Performance

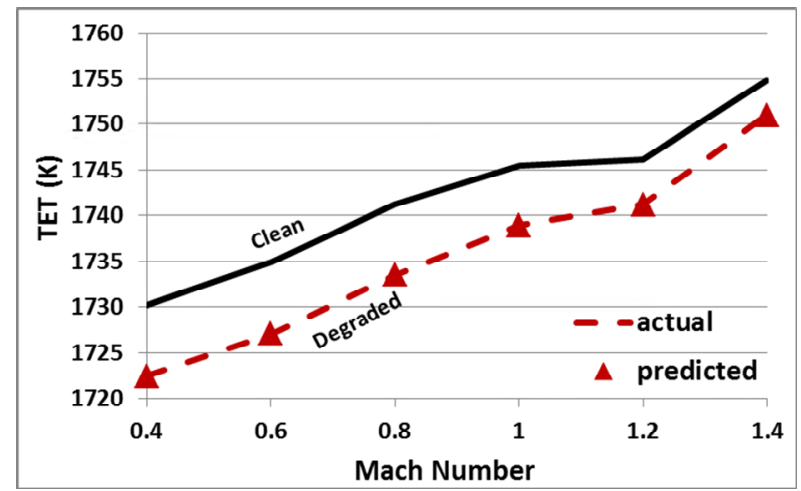

Figure 17: Prediction of TET of Degraded Engine at $\mathrm{H}=8 \mathrm{~km}$ and its Comparison with Actual Performance

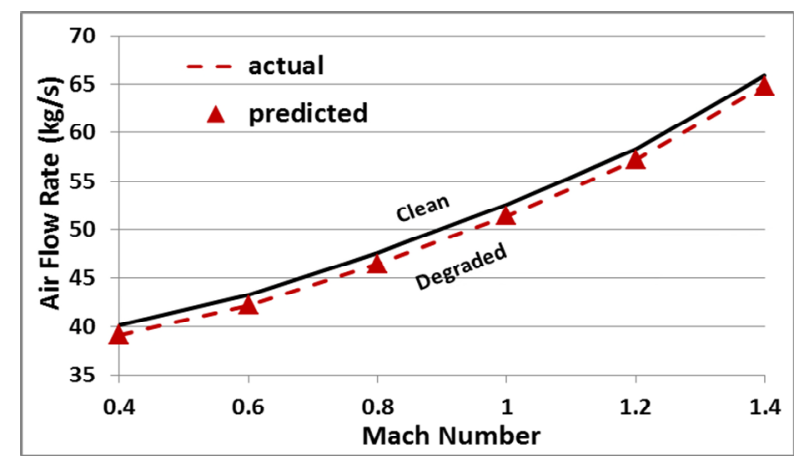

Figure 18: Prediction of Air Flow Rate of Degraded Engine at $\mathbf{H}=\mathbf{8 k m}$ and its Comparison with Actual Performance 


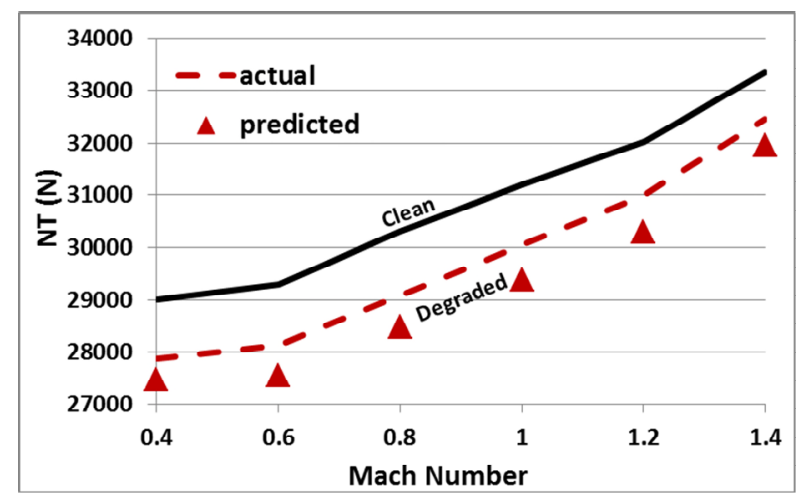

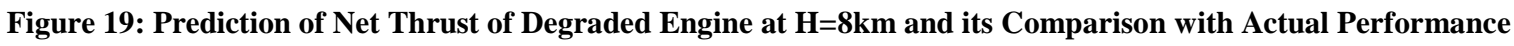

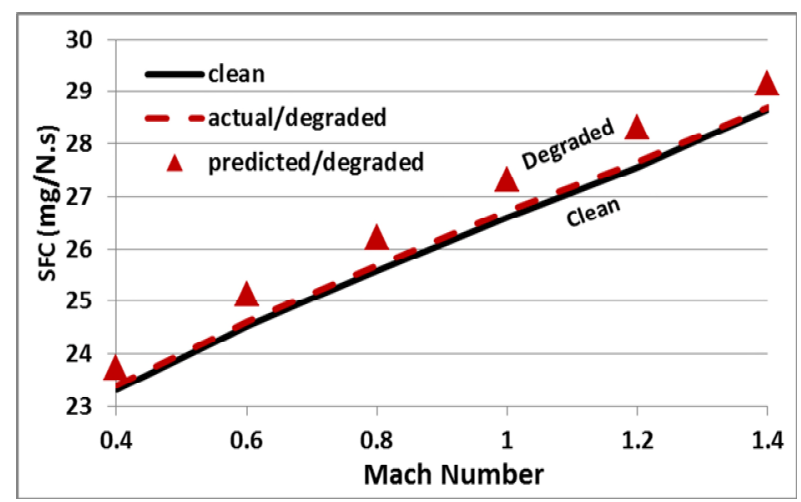

Figure 20: Prediction of $S F C$ of Degraded Engine at $\mathrm{H}=8 \mathrm{~km}$ and its Comparison with Actual Performance

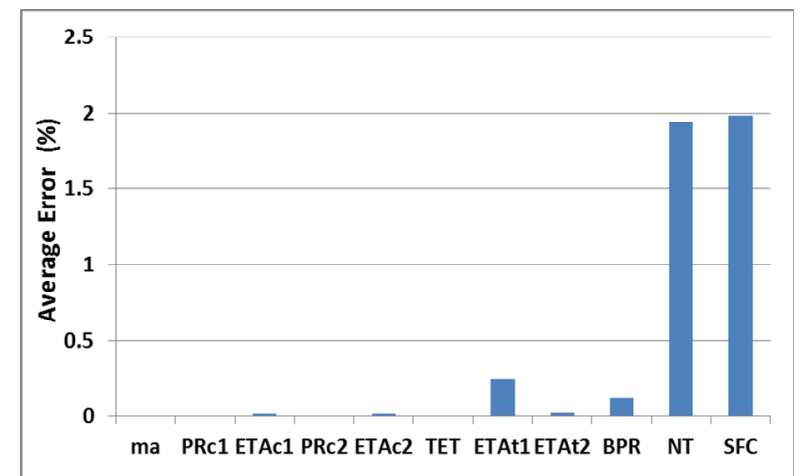

Figure 21: Average Prediction Errors for Performance Parameters of Degraded Engine at H=8km 


\section{F. Performance Estimation of Engine at Part-Load}

The gas path measurements simulated with the engine model operating at part-load at sea level static ISA condition are described in Section $\mathrm{C}$ and an example of the simulated measurements is shown in Figures 8 and 9. They were used as the input information for the performance estimation of the model engine at part-load.

The most important engine performance parameters of the model engine at part-load, such as TET, engine air flow rate, SFC and net thrust NT varying with the engine handle (the HP shaft rotational speed PCN2), were predicted with the introduced performance estimation method and are shown in Figures 22 to 24, respectively. They are also compared with the actual values of the same parameters in these figures. The average prediction errors defined by Equation (11) of the engine performance parameters at the part load are shown in Figure 25. It can be seen that the prediction errors for most performance parameters are below $0.1 \%$ while the errors for the net thrust and the SFC are relatively large, around $2.3 \%$.

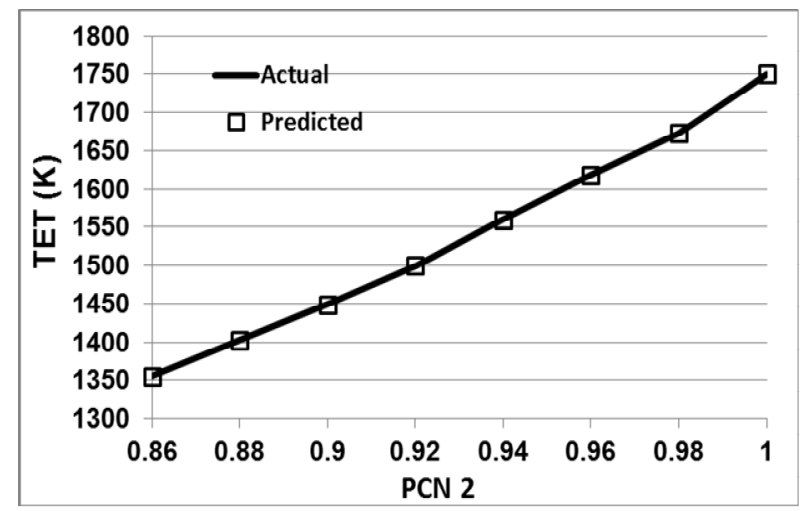

Figure 22: Prediction of TET of Engine at Part Load

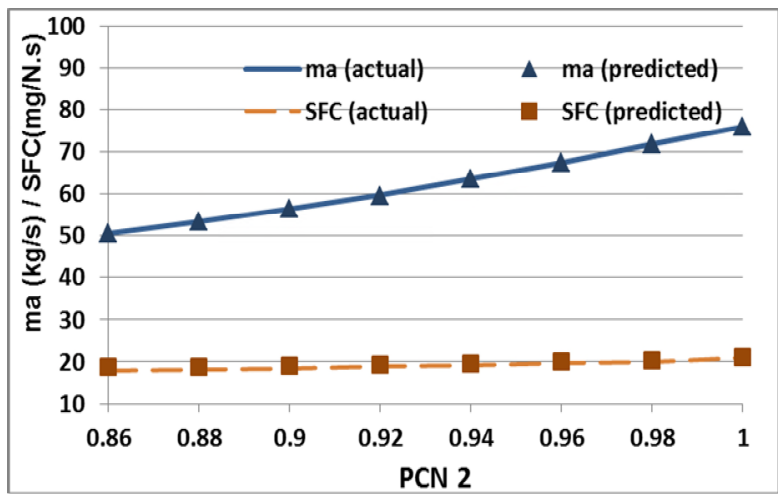

Figure 23: Prediction of $m_{f}$ and $S F C$ of Engine at Part Load 


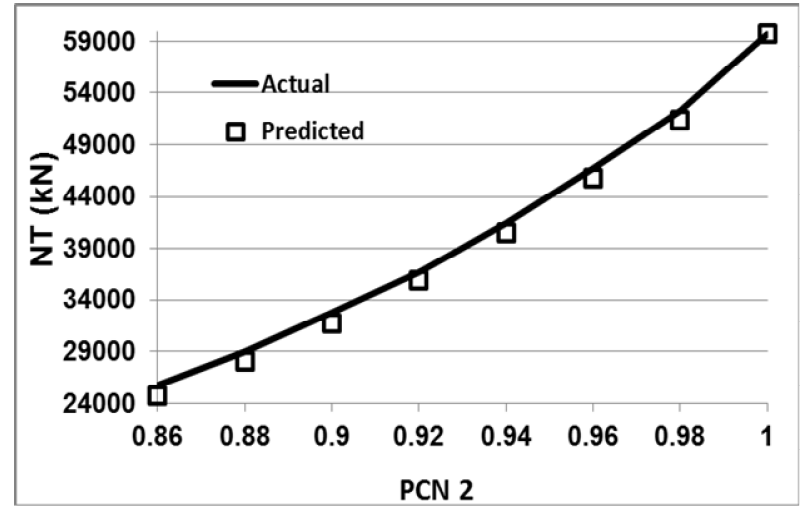

Figure 24: Prediction of NT of Engine at Part Load

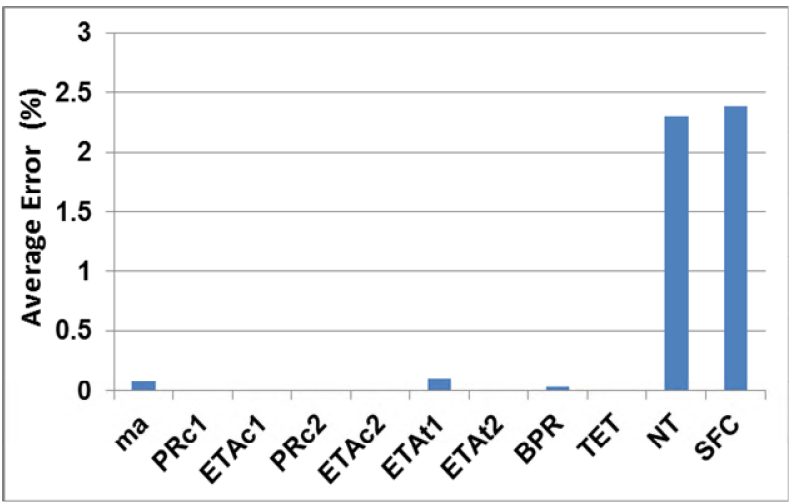

Figure 25: Average Prediction Errors of Performance Parameters at Part Load

\section{G. Impact of Measurement Noise}

To analyse the impact of measurement noise on the accuracy of performance estimation, a measurement noise model with the maximum levels of measurement noise shown in Table 5 was implemented into Pythia to simulate measurement samples with the inclusion of measurement noise. The measurement noise was randomly generated following Gaussian type distribution and was imposed on the true values of the gas path measurement parameters to represent the measurement samples with measurement noise. In this study, 10 sets of random samples of the gas path measurement parameters (Table 2) with the inclusion of measurement noise were generated at altitude of $12 \mathrm{~km}$ and Mach number 1.2 and the samples of one of the gas path parameters $T_{24}$ is shown in Figure 29 where Point 11 shows the true value of $T_{24}$. 
Table 5 Maximum Measurement Noise [20]

\begin{tabular}{|c|c|c|}
\hline Measurement & Range & Typical Error \\
\hline Pressure & $\begin{array}{l}0.204-3.06 \mathrm{~atm} \\
0.544-31.30 \mathrm{~atm}\end{array}$ & $\begin{array}{l} \pm 0.5 \% \\
\pm 0.5 \% \text { or } 0.125 \\
\text { atm whichever is } \\
\text { greater }\end{array}$ \\
\hline Temperature & $\begin{array}{l}-65-290{ }^{\circ} \mathrm{C} \\
290-1000{ }^{\circ} \mathrm{C} \\
1000-1300^{\circ} \mathrm{C}\end{array}$ & $\begin{array}{l} \pm 3.3^{\circ} \mathrm{C} \\
\pm \sqrt{2.5^{2}+(0.0075 \cdot T)^{2}} \\
\pm \sqrt{3.5^{2}+(0.0075 \cdot T)^{2}}\end{array}$ \\
\hline Fuel Flow & $\begin{array}{l}\text { Up to } 250 \mathrm{~kg} / \mathrm{hr} \\
\text { Up to } 450 \mathrm{~kg} / \mathrm{hr} \\
\text { Up to } 900 \mathrm{~kg} / \mathrm{hr} \\
\text { Up to } 1360 \mathrm{~kg} / \mathrm{hr} \\
\text { Up to } 1815 \mathrm{~kg} / \mathrm{hr} \\
\text { Up to } 2270 \mathrm{~kg} / \mathrm{hr} \\
\text { Up to } 2725 \mathrm{~kg} / \mathrm{hr} \\
\text { Up to } 3630 \mathrm{~kg} / \mathrm{hr} \\
\text { Up to } 5450 \mathrm{~kg} / \mathrm{hr} \\
\text { Up to } 12260 \mathrm{~kg} / \mathrm{hr}\end{array}$ & $\begin{array}{l}41.5 \mathrm{~kg} / \mathrm{hr} \\
34.3 \mathrm{~kg} / \mathrm{hr} \\
29.4 \mathrm{~kg} / \mathrm{hr} \\
23.7 \mathrm{~kg} / \mathrm{hr} \\
20.8 \mathrm{~kg} / \mathrm{hr} \\
23.0 \mathrm{~kg} / \mathrm{hr} \\
25.9 \mathrm{~kg} / \mathrm{hr} \\
36.2 \mathrm{~kg} / \mathrm{hr} \\
63.4 \mathrm{~kg} / \mathrm{hr} \\
142.7 \mathrm{~kg} / \mathrm{hr}\end{array}$ \\
\hline
\end{tabular}

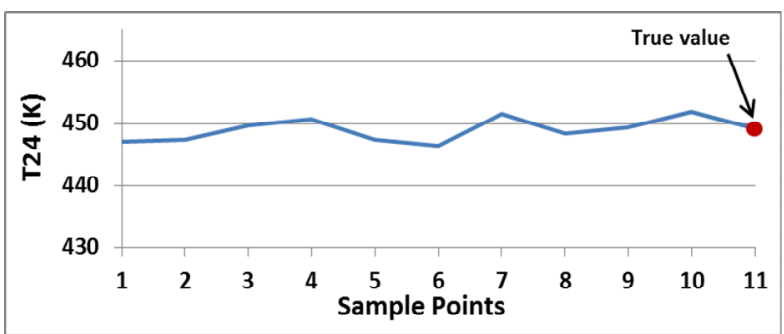

Figure 26: Measurment Samples of $T_{3}$ with Measurment Noise 
Using the performance estimation method shown in Section II, the engine performance parameters were estimated using the ten noisy samples. The predictions of two of the performance parameters, the Turbine entry temperature (TET) and the Net Thrust $(N T)$, of the model engine are shown in Figures 27 and 28 where Point 11 shows the true values of TET and NT.

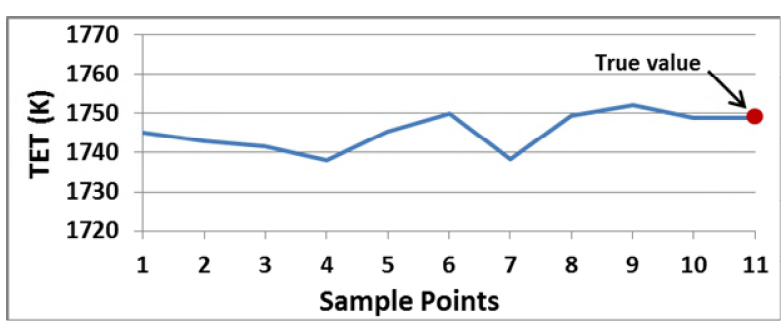

Figure 27: Predicted Turbine Entry Temperatue (TET)

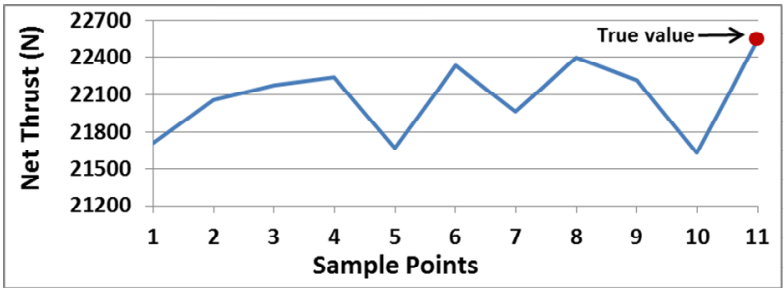

Figure 28: Predicted Net Thrust (NT)

The average prediction errors calculated with Equation (11) for the engine performance parameters in concern are shown in Figure 29. A comparison of the average prediction errors between Figure 29 and Figures 15 and 25 shows that the measurement noise does increase the prediction errors of the performance parameters. However it can be seen that the prediction errors for the compressor pressure ratios $(P R)$ and the Turbine Entry Temperature (TET) are still very small, which are below $0.3 \%$ while the prediction errors for the engine air flow rate $\left(m_{a}\right)$, the isentropic efficiency $\left(E T A_{t 2}\right)$ of the LPT, the Net Thrust $(N T)$ and the SFC are around $2 \%$. The largest prediction error happens to the bypass ratio $(B P R)$, which is around $9.5 \%$. 


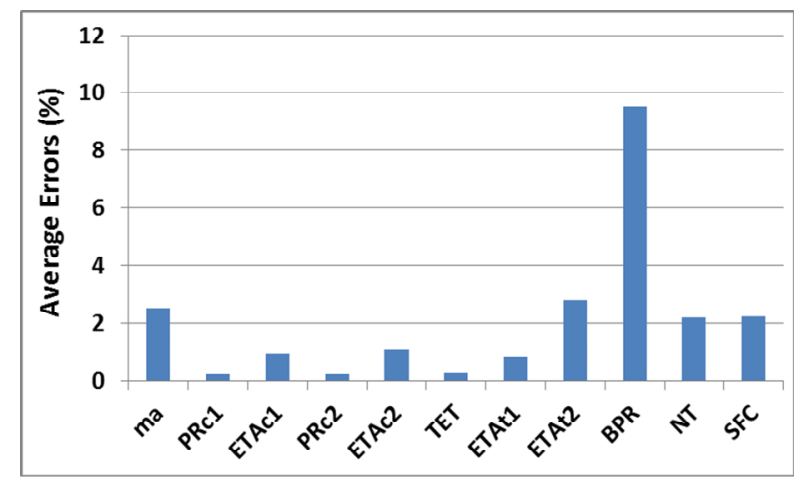

Figure 29: Average Prediction Errors Including the Impact of Measurement Noise

\section{H. Calculation Speed}

The performance estimation involves mathematical iterations of matrix inverse calculations and the use of complicated non-linear thermodynamic calculations; it is inevitable that certain amount of computation time is required. It takes around 13 iterations in around 30 seconds for the calculation of a typical point using a laptop computer with duo Intel ${ }^{\circledR}$ Core ${ }^{\mathrm{TM}}$ i7-3520M processors and $\mathrm{CPU}$ of $2.9 \mathrm{GHz}$. Such performance estimation approach should be quick enough and satisfactory for off-line condition monitoring purpose but not fast enough for online real-time applications. To speed up the calculation speed, linear performance estimation approach and simplified thermodynamic models may be used but the accuracy of the performance estimation will suffer significantly.

\section{CONCLUSIONS}

A novel performance estimation method based on Influence Coefficient Matrix (ICM) for gas turbine engines using engine gas path measurements is introduced in this paper and it has been applied to the performance estimation of a model aero low bypass turbofan engine using simulated gas path measurements to test the effectiveness of the method. Based on the work conducted in this research, it can be concluded that the introduced method is effective and is able to provide accurate estimation of performance parameters of gas turbine engines at different flight, engine health and part-load operating conditions. It provides the capability of making important invisible gas path performance parameters visible to gas turbine users, which is a useful complement to current engine condition monitoring techniques. The introduced method has the advantage that no component 
characteristic maps are required and therefore the performance estimation is relatively simple and fast, which is very desirable for engineering applications. The average prediction errors for most performance parameters are below $0.4 \%$ with the exception that the average prediction errors for the net thrust and the SFC are within $2 \%$ without considering the impact of measurement noise of the gas path measurements. The measurement noise has a negative impact on the accuracy of the estimation - around $0.3-2 \%$ for most performance parameters and around 9.5\% for bypass ratio. The calculation time for the performance estimation is around 30 seconds for a typical prediction point involving around 13 iterations by using a modern laptop computer, which is suitable for off-line engine condition monitoring applications. In theory, the introduced performance estimation method can be applied to any types of gas turbine engines.

\section{REFERENCES}

1. Koenig, R.W. and Fishbach, L.W., "GENENG - A Program for Calculating Design and Off Design Performance for Turbojet and Turbofan Engines", NASA, TND-6552, 1972.

2. Fishbach, L.W. and Koenig, R.W., "GENENG II - A Program for Calculating Design and Off Design Performance of Two and Three-Spool Turbofans With as Many Nozzles”, NASA, TN D-6553, 1972.

3. MacMillan, W., "Development of a Modular Type Computer Program for the Calculation of Gas Turbine Off Design Performance", PhD thesis, Cranfield Institute of Technology, 1974.

4. Stamatis A., Mathioudakis K. and Papailiou K., "Adaptive Simulation of Gas Turbine Performance", Journal of Engineering for Gas Turbines and Power, Vol. 112, 1990, pp. 168.

5. Stamatis A., Mathioudakis K. and Papailiou K., "Optimal Measurement and Health Index Selection for Gas Turbine Performance Status and Fault Diagnosis", Journal of Engineering for Gas Turbines and Power, Vol. 14, No. 2, 1992.

6. Lambiris B., Mathioudakis K., Stamatis A. and Papailiou K., "Adaptive modeling of jet engine performance with application to condition monitoring", Journal of Propulsion and Power, Vol. 10, No. 6, 1994, pp. 890896.

7. Roth B., Doel D. L., Mavris D. and Beeson D., "High-Accuracy Matching of Engine Performance Models to Test Data”, GT2003-38784, ASME Turbo Expo 2003, 2003. 
8. Roth B. A., Doel D. L. and Cissell J. J., "Probabilistic Matching of Turbofan Engine Performance Models to Test Data”, GT2005-68201, ASME Turbo Expo 2005, 2005.

9. Kong C., Kho S. and Ki J., “Component Map Generation of a Gas Turbine Using Genetic Algorithm”, GT2004-53736, ASME Turbo Expo 2004, 2004.

10. Kong C. and Ki J., “Component Map Generation of Gas Turbine Engine Using Genetic Algorithm and Engine Performance Deck Data”, Journal of Engineering for Gas Turbines and Power, Vol.129, No.2, 2007, pp312317.

11. Li Y. G., Pilidis, P. and Newby, M. A., "An Adaptation Approach for Gas Turbine Design-Point Performance Simulation", Journal of Engineering for Gas Turbines and Power, Vol. 128, pp. 789, 2006.

12. Li Y. G., Marinai L., Gatto E. L., Pachidis V. A. and Pilidis P., "Multiple Point Adaptive Performance Simulation Tuned to Aerospace Test-Bed Data," Journal of Propulsion and Power, Vol. 25, No. 3, p. 635, 2009.

13. Li Y. G., Abdul Ghafir M. F., Wang L., Singh R., Huang K., and Feng X., "Non-linear multiple points gas turbine off-design performance adaptation using a genetic algorithm," ASME Journal of Engineering for Gas Turbines and Power, Vol. 133, No. 7, pp.071701, 2011.

14. Li Y. G., Abdul Ghafir M. F., Wang L., Singh R., Huang K., Feng X. and Zhang W., "Improved Multiple Point Non-Linear Genetic Algorithm Based Performance Adaptation Using Least Square Method”, ASME Journal of Engineering for Gas Turbines and Power, Vol.134, pp.031701, 2012.

15. Tsoutsanis E., Li Y.G., Pilidis P. and Newby M., "Part-load performance of gas turbines - Part I: A novel compressor map generation approach suitable for adaptive simulation”, ASME Gas Turbine India Conference, GTIndia-9580, Mumbai, Maharashtra, India, December 2012.

16. Tsoutsanis E., Li Y.G., Pilidis P. and Newby M.,"Part-load performance of gas turbines - Part II:Multi-point adaptation with compressor map generation and GA optimization", ASME Gas Turbine India Conference, GTIndia-9581, Mumbai, Maharashtra, India, December 2012.

17. Tsoutsanis E., Meskin N., Benammar M. and Khorasani K., “An effective component map generation method for prediction of gas turbine performance”, GT2014-25753, ASME Turbo Expo conference, Dusseldorf, Germany, June 2014.

18. Escher P. C. and Singh R., “An Object-Oriented Diagnostics Computer Programme Suitable for Industrial Gas Turbines", $21^{\text {st }}$ (CIMAC) International Congress of Combustion Engines, Switzerland, 1995. 
19. Li Y. G. and Singh R., “An Advanced Gas Turbine Gas Path Diagnostic System - PYTHIA”, ISABE-20051284, the $17^{\text {th }}$ International Symposium on Airbreathing Engines (17 ${ }^{\text {th }}$ ISABE), Munich, Germany, 2005.

20. Dyson R.J.E. and Doel D. L., “CF-80 Condition Monitoring - The Engine Manufacturing's Involvement in Data Acquisition and Analysis", AIAA-84-1412, 1987. 
2015-01-05

\section{Aero gas turbine flight performance estimation using engine gas path measurements}

Li, Yi-Guang

AIAA

Yi-Guang Li. (2015) Aero gas turbine flight performance estimation using engine gas path

measurements. Journal of Propulsion and Power, Volume 31, Issue 3, May 2015, pp. 851-860

https://doi.org/10.2514/1.B35381

Downloaded from Cranfield Library Services E-Repository 